\title{
Rozenholc Caroline, Tel-Aviv. Le quartier de Florentine : un ailleurs dans la ville
}

Denis Charbit

\section{(2) OpenEdition \\ 1 Journals}

Édition électronique

URL : https://journals.openedition.org/remi/16201

DOI : 10.4000/remi. 16201

ISSN : $1777-5418$

Éditeur

Université de Poitiers

\section{Édition imprimée}

Date de publication : 30 décembre 2020

Pagination : 353-355

ISBN : 979-10-90426-67-2

ISSN : 0765-0752

\section{Référence électronique}

Denis Charbit, "Rozenholc Caroline, Tel-Aviv. Le quartier de Florentine : un ailleurs dans la ville », Revue européenne des migrations internationales [En ligne], vol. 36 - n² 2 et 3 | 2020, mis en ligne le 01 janvier 2021, consulté le 04 janvier 2023. URL : http://journals.openedition.org/remi/16201 ; DOI : https:// doi.org/10.4000/remi.16201

Ce document a été généré automatiquement le 4 janvier 2023.

Tous droits réservés 


\section{Rozenholc Caroline, Tel-Aviv. Le quartier de Florentine : un ailleurs dans la ville}

Denis Charbit

\section{RÉFÉRENCE}

Rozenholc Caroline (2018) Tel-Aviv. Le quartier de Florentine : un ailleurs dans la ville. -

Paris : Créaphis éditions. - 240 p., ISBN : 978-2-354-28123-6

1 Depuis plus d'une décennie, Tel-Aviv a acquis un prestige international conféré par son statut de "ville globale ». Cette ouverture sur le monde extérieur, notamment dans le domaine de l'innovation technologique, est allée de pair avec l'inscription de la « ville blanche " au patrimoine de l'UNESCO en 1994. C'est par ce vocable, dont Tel-Aviv ne détient pas l'exclusivité (puisqu'il s'applique également à Alger, Casablanca et Chicago), qu'on a baptisé la rénovation d'une partie substantielle du patrimoine architectural de la ville composé d'immeubles érigés dans le plus pur style Bauhaus pour répondre à la demande consécutive au flux migratoire en Palestine de plus de 250000 juifs fuyant le nazisme et le fascisme en Europe à la veille de la Seconde Guerre mondiale. Dans la foulée de cette rénovation réussie qui révélait aux habitants l'existence de ce patrimoine, on a procédé à celle d'un autre quartier, Neve Tsedek, construit, à la fin du XIXe siècle, indépendamment de l'entreprise sioniste. Là aussi, la transformation a été spectaculaire : sous les coups de boutoir d'un processus de gentrification accéléré, le taudis défavorisé, pauvre et insalubre, situé à deux pas du front de mer, est devenu un quartier huppé conservant sa touche d'« authenticité ».

2 L'originalité du travail de recherche effectué par Caroline Rozenholc est d'avoir choisi comme lieu d'observation pour tester ses hypothèses sur les rapports entre le global et le local, ni la Ville blanche ni Neve Tsedek, mais un quartier limitrophe, Florentine. Situé entre Neve Tsedek et Jaffa, il n'avait guère été intégré au schéma directeur établi 
par Patrick Geddes en 1926 dans le cadre du Mandat britannique en Palestine. Relégué aux marges, Florentine, cet entre-deux, cet interstice fut longtemps négligé par les autorités municipales et les pouvoirs publics qui avaient privilégié la promotion du centre et du nord de la ville. Espace d'habitation des dockers juifs originaires de Salonique venus s'établir en Palestine dans l'entre-deux-guerres, Florentine était resté un quartier d'artisans et de petits commerçants spécialisés dans l'ameublement à bon marché, voué au déclin qui paraissait inexorable. Il fut cependant réinvesti au début des années 1990 par des populations en quête d'un toit à bas prix : des travailleurs étrangers venus d'Afrique et d'Asie avec l'ouverture des frontières d'Israël à la maind'œuvre étrangère, consécutive au bouclage répété de la bande de Gaza et de Cisjordanie ; une population étudiante et bohème, de retour au bercail après le grand voyage en Inde ou en Amérique latine effectué après le service militaire, en plus de la population locale originelle des Balkans, plutôt traditionalistes, et même des Palestiniens de Cisjordanie venus se réfugier avec leur famille à Florentine après avoir été dénoncés comme indicateurs pour les services de sécurité israélienne. Cet improbable patchwork a pourtant réussi à insuffler au quartier un nouveau dynamisme, pour ne pas dire une résurrection.

3 Comment s'est opérée la renaissance du quartier? Quelle part ces populations ont-elles prise dans le processus au point de lui conférer une identité propre qui condense, à sa manière, l'éthos israélien et l'a transformé simultanément par les modes de vie et de style de vie apportés à cette diversité ethnique, religieuse et linguistique ? Comment s'est opérée la fusion entre les traces du passé récent et les signes du changement ? Comment les habitants ont-ils résisté à leur éviction progressive souhaitée par des promoteurs immobiliers avides de reproduire à Florentine ce qui s'était passé à Neve Tsedek? Pour répondre à ces questions, Caroline Rozenholc ne s'est pas contentée d'une enquête sur le terrain, d'un travail de type ethnologique sur la faune de Florentine. Au lieu de n'être que le miroir d'une discipline stricte, son livre, qui relève stricto sensu de la géographie urbaine dont elle est spécialiste, croise l'histoire politique, l'analyse culturelle et la sémiologie. Pour décrire et expliquer l'hybridité des processus, elle a choisi une méthodologie hybride également, qui mobilise les sciences sociales afin de trouver des explications neuves et pertinentes à des processus contradictoires et complémentaires. Le chapitre sur l'art mural à Florentine, avec ses tags, graffitis et pochoirs, en tout genre et en plusieurs langues, illustre parfaitement ce croisement entre pratique créatrice, engagement politique et diffusion spontanée, grâce auxquels les habitants se sont approprié l'espace public et ont singularisé leur quartier. Le travail de Caroline Rozenholc nous permet de penser une subtile dialectique entre ici et ailleurs, entre privé et public, mais surtout entre marginalité et intégration, ce dont témoigne une fonctionnaire municipale qui se dit stimulée par la mobilisation des habitants du quartier devenus ses interlocuteurs privilégiés. L'auteure rend palpable ce phénomène intriguant d'un quartier hétérogène qui invente et construit son identité, non dans le repli et l'altérité, mais en brassant en permanence des apports multiples, en développant des modes de sociabilité qui poussent à la proximité, à l'échange, à l'insouciance, préservant une coexistence pacifique entre le restaurant populaire et le sushi-bar, entre l'épicerie de quartier et la supérette. Florentine réinvente la solidarité communautaire dont le kibboutz avait été autrefois le fleuron, sans développer parallèlement le côté insulaire qui isolait le kibboutz de son environnement immédiat et a fini par le condamner. Ainsi, il n'y a pas d'opposition binaire entre mondialisation et patrimonialisation, et Florentine n'est pas coincée par 
l'alternative proposée par Benjamin Barber entre le Mac World et le Djihad. Le développement de Florentine s'inscrit à la fois dans une dynamique de globalisation du quartier, mais également dans une inscription locale qui se traduit par la résurgence de l'option méditerranéenne dans l'horizon des possibles culturels de la société israélienne.

Le lecteur retiendra en particulier le décalage qui existe, non seulement entre l'État et la société civile - ce qui a été largement repéré et documenté - mais également entre l'État et le pouvoir local. Certes, cette réalité inédite est le fait de villes, comme TelAviv, disposant d'une large autonomie financière et d'une marge de manœuvre qui l'autorise à impulser des politiques en contradiction avec celles de l'État: les décisions de la municipalité de Tel-Aviv en faveur de l'intégration des travailleurs immigrés et des réfugiés ont préfiguré un accès à la citoyenneté inédit et à un droit du sol qui fut, au demeurant, partiellement appliqué par le gouvernement centriste d'Ehoud Olmert entre 2006 et 2009, avant d'être définitivement banni par les gouvernements successifs dirigés par Benjamin Netanyahou. Plus largement, l'essor de la «ville noire», dans le sillage de la ville blanche, illustre aussi le paradoxe d'un néo-libéralisme avancé qui, en même temps qu'il accroît les inégalités, tend à effacer les frontières entre les groupes sociaux et rend plus visibles des populations autrefois laissées-pour-compte. La conquête du Sud n'a pas abouti à sa reddition aux forces du marché, mais a suscité en retour des pratiques de résistance et d'accommodement qui montrent la vitalité du social à une ère de stagnation politique. Cependant, la contestation indéniable des grands récits et des mythes fondateurs et la construction dans les limbes d'une identité postnationale restent encore sans débouché politique qui en ferait une vraie alternative.

5 Je n'ai relevé dans le livre que trois erreurs, toutes mineures : la première Intifada a été déclenchée en 1987 (p. 143) ; ce n'est pas Netanyahou qui a mené une opération au Liban après son entrée en fonction en juin 1996, mais Shimon Pérès, deux mois plus tôt (p.65); enfin le pochoir qui orne le slogan «ne détruisez pas son quartier» (p. 167, fig. 31) n'est pas une référence empruntée au Kid de Charles Chaplin, mais à une image devenue icône en Israël dans les années qui ont suivi la guerre du Kippour: Hayeled habokhé (L'enfant en pleurs). C'est dire combien la géographe a démontré une maitrise et une expertise exceptionnelle dans des domaines contigus à sa discipline : l'histoire du yichouv et d'Israël, les politiques d'immigration, les représentations culturelles, mobilisant, en plus d'une connaissance d'Israël et du sionisme, un solide appareil théorique pour tisser la grande toile de fond qu'elle confronte en permanence au microcosme Florentine en pleine métamorphose. Notons enfin le choix éditorial hautement significatif de représenter le quartier, non par des photos, pour ne pas dire des clichés, mais par des croquis. On ne pouvait imaginer un choix plus pertinent pour faire valoir cette idée-force qui circule tout au long de l'ouvrage : la vie dans la ville est mouvement et circulation, et il est plus approprié d'en rendre compte par des traits et des traces au crayon qui lui confère fluidité et intemporalité que par des représentations photographiques qui l'auraient figée dans le temps.

Le livre lu et refermé, on s'interroge sur l'exemplarité de Tel-Aviv: est-elle une «bulle », un laboratoire en vase clos, qui ne vaut guère pour l'ensemble d'Israël ou bien, comme l'auteur le suggère, cette hétérogénéité de classes d'âge, d'ethnies, de religions et de langues, a-t-elle un impact qui va au-delà de Florentine et de la ville et dessine un ailleurs possible? Ces marges et ces écarts, ces éclats et ces fulgurances, ces 
esquisses inachevées sont-ils la dernière utopie en cours qui s'est fixé à Florentine un unique port d'attache? Est-ce à Florentine que se répand le souffle pionnier d'une nouvelle société?

\section{AUTEURS}

\section{DENIS CHARBIT}

Département de sociologie, science politique et communication, Open University of Israel 